\title{
Diagnosis and Management of High-Risk Breast Lesions
}

\author{
Parijatham S. Thomas, MD
}

\begin{abstract}
Atypical hyperplasia (AH) and lobular carcinoma in situ (LCIS) are nonmalignant breast lesions that confer a 4- to 10-fold increased risk for breast cancer in women. Often, AH and LCIS are diagnosed through breast biopsy due to a mammographic or palpable finding. Although $\mathrm{AH}$ and LCIS are benign breast disease, further management is necessary due to their high-risk nature and premalignant potential. Over the decades, management of AH and LCIS has changed as more is learned about these disease processes. This review explores the studies evaluating the risk for breast cancer in women with AH or LCIS and the clinical management of these lesions, which can include a combination of surgical excision, surveillance, and risk-reduction therapy.
\end{abstract}

J Natl Compr Canc Netw 2018;16(11):1391-1396 doi: 10.6004ljnccn.2018.7099

Benign breast disease is often diagnosed through biopsy performed as a result of concerning mammographic or palpable findings. More than 1 million US women undergo breast biopsies annually due to these concerns, with $>70 \%$ of the results revealing benign disease. ${ }^{1}$ However, not all benign breast biopsies are equal, and certain lesions confer an increased risk for breast cancer. Specifically, lesions with atypical hyperplasia (AH) and lobular carcinoma in situ (LCIS) have been shown to be associated with a higher risk for future breast cancer and to be precursors in breast carcinogenesis. ${ }^{2-5}$ Recent data have also shown a high cumulative breast cancer incidence of $30 \%$ at 25 years of follow-up in women with $\mathrm{AH}{ }^{3}$

Management of these high-risk lesions is essential in breast cancer prevention. This review discusses the clinical presentation and histologic diagnosis of $\mathrm{AH}$ and LCIS, and examines the risk for invasive breast cancer associated with and management of these lesions, including surgical excision, surveillance, and riskreduction therapy.

\section{Clinical Presentation and Histologic Features}

In the initial study by Dupont and Page, ${ }^{6}$ which noted that breast lesions with atypia carried a higher risk for breast cancer, breast biopsies were predominately performed on palpable masses and only $3.6 \%$ of the biopsies showed atypia. In the current era of breast cancer screening with digital mammography, recent studies have shown that approximately $10 \%$ of all benign breast biopsies show $\mathrm{AH} .{ }^{7}$ In a study evaluating biopsies performed as a result of calcifications noted on mammogram, $\mathrm{AH}$ was detected in $12 \%$ to $17 \%$ of patients. ${ }^{8} \mathrm{AH}$ and LCIS lesions often present as a mammographic abnormality, indicating the importance of breast cancer screening with annual mammogram to identify highrisk patients.

Atypical ductal hyperplasia $(\mathrm{ADH})$ is defined as distended ducts filled with a proliferation of monotonous epithelial cells with round nuclei forming architecturally complex patterns. ${ }^{9}$ Low-grade ductal carcinoma in situ (DCIS) contains similar histologic features to ADH but tends to be more exten-

products discussed in this article or their competitors.

Correspondence: Parijatham S. Thomas, MD, Department of Clinical Cancer Prevention, The University of Texas MD Anderson Cancer Center, 1515 Holcombe Boulevard, Unit 1360, Houston, TX 77030.

Email: psthomas@mdanderson.org 
sive. Since differences in diagnosis of ADH or DCIS is dependent on the extensiveness of disease, surgical excision is often recommended for a definitive diagnosis. Atypical lobular hyperplasia (ALH) is composed of monomorphic cells that are round or oval and usually evenly spaced with eccentric nuclei and lack cohesion. ${ }^{5}$ They are present in fewer than onehalf of the acini of a lobular unit that is distorted or distended. LCIS is similar to ALH but contains more extensive disease and is associated with a higher risk of breast cancer. Loss of the cell-cell junction protein, E-cadherin, is noted in ALH, LCIS, and invasive lobular carcinoma and can help distinguish from ductal phenotypes through immunohistochemistry. Estrogen receptor (ER) expression was evaluated by Barr et $\mathrm{al}^{10}$ in $\mathrm{AH}$ and found that $97 \%$ of $\mathrm{ADH}$ lesions and $88 \%$ of ALH lesions were positive for ER staining in $\geq 10 \%$ of the cells.

\section{Risk of Breast Cancer}

In 1985, Dupont and Page $^{6}$ showed an elevated risk for breast cancer in women with AH and LCIS using the Nashville Breast Cohort, in which they followed $>3,000$ women with benign breast biopsies. They found that women with proliferative breast disease and atypia had a relative risk (RR) of 5.3 (95\% CI, 3.1-8.8) compared with those without atypia. Similar findings have been confirmed in other cohorts (Table 1). The absolute risk for breast cancer is approximately $1 \%$ to $2 \%$ per year for women with ALH and $\mathrm{ADH}$ and $2 \%$ per year in those with LCIS. ${ }^{11-13}$ Coopey et $\mathrm{a}^{11}$ estimated a 10 -year risk of breast cancer of $21 \%$ in these women. Hartmann et $\mathrm{al}^{3,5} \mathrm{fol}$ lowed women in the Mayo Clinic Benign Breast Disease cohort and found a cumulative incidence of $30 \%$ for invasive breast cancer after 25 years of follow-up in those with AH or LCIS. These recent findings confirmed previous studies and indicate that the risk persists long-term.

\section{Risk Modifiers}

Multiple studies have evaluated whether clinical or histologic factors modify the risk of breast cancer in patients with $\mathrm{AH} / \mathrm{LCIS}$. Age at $\mathrm{AH}$ diagnosis has been shown to affect risk, with those diagnosed at a younger age, such as premenopausal women, more likely to develop breast cancer. ${ }^{3,14}$ However, recent data from Mazzola et $\mathrm{a}^{15}$ showed that the 15-year cancer risk in women with atypia was not significantly different among various age groups. Family history of breast cancer has been evaluated in women who also have AH/LCIS, with mixed findings reported. Dupont and Page ${ }^{6}$ noted that a subset of women with $\mathrm{AH}$ and a family history of breast cancer had an RR of breast cancer of 8.9 (95\% CI, 4.8-17) compared with 3.5 (95\% CI, 2.3-5.5) in women with $\mathrm{AH}$ and no family history. However, data from the Nurses' Health Study and Mayo Clinic Benign Breast Disease Cohort did not show a significant difference in $\mathrm{RR}$ of breast cancer due to family history in women with $\mathrm{AH} .{ }^{3,16}$

Increased mammographic density has been noted to be an independent risk factor for breast cancer. Ghosh et $\mathrm{al}^{17}$ evaluated the association between mammographic breast density and benign breast disease. They assessed breast density using BI-RADS categories and found that increased breast density was noted in those with high-risk breast lesions, such as ALH. Women with ALH had a $50 \%$ greater chance of having dense breasts than

Table 1. RR of Breast Cancer After Diagnosis of AH

\begin{tabular}{|c|c|c|c|c|c|}
\hline \multirow[b]{2}{*}{ Study } & \multirow[b]{2}{*}{$\mathbf{N}$} & \multirow{2}{*}{$\begin{array}{l}\text { Median Follow-Up } \\
\text { Duration, y }\end{array}$} & \multicolumn{3}{|c|}{$\begin{array}{l}\text { RR of Breast Cancer } \\
(95 \% \mathrm{Cl})\end{array}$} \\
\hline & & & ADH & ALH & All AH \\
\hline Nashville Breast Cohort, $1985^{6,50}$ & 232 & 17 & $4.7(2.5-8.9)$ & $5.8(3.0-11.0)$ & $4.4(3.1-6.3)$ \\
\hline Nurses' Health Study, $1992^{14}$ & 74 & 8 & - & - & $3.7(2.1-6.8)$ \\
\hline Nurses' Health Study, $2007^{16}$ & 96 & 9.1 & $3.09(2.01-4.75)$ & $5.49(3.29-9.18)$ & $4.11(2.9-5.83)$ \\
\hline Henry Ford Health System, $2007^{51}$ & 246 & - & $5.0(2.3-11.0)$ & $3.2(0.83-12.4)$ & $4.6(2.93-7.37)$ \\
\hline Mayo Benign Breast Disease Cohort, $2014^{3}$ & 698 & 12.5 & $3.93(3.0-5.06)$ & $4.76(3.74-5.97)$ & $4.34(3.66-5.12)$ \\
\hline Breast Cancer Surveillance Consortium, $2017^{12}$ & 1,727 & 10 & $2.6(2.0-3.4)^{\mathrm{a}}$ & - & - \\
\hline
\end{tabular}

Abbreviations: $A D H$, atypical ductal hyperplasia; $\mathrm{AH}$, atypical hyperplasia; $\mathrm{ALH}$, atypical lobular hyperplasia; $\mathrm{RR}$, relative risk.

aHazard ratios reported. 
those without (odds ratio, 1.5; 95\% CI, 1.2-2.1; $P=.05$ ), but $\mathrm{ADH}$ was not found to be associated with dense breast tissue. ${ }^{17}$ An association between breast density and risk of breast cancer in women with $\mathrm{AH}$ was not found. ${ }^{18}$

Histologic features, such as number of foci affected and involution of lobules, have been shown to stratify the risk of breast cancer in women with $\mathrm{AH}$. Hartmann et $\mathrm{al}^{3,5}$ showed an increase in the cumulative incidence of breast cancer in women with $\mathrm{AH}$, with increasing number of separate foci affected with atypia. Women with $\geq 3$ atypical foci had a $46.6 \%$ risk of breast cancer at 25 years compared with $23.9 \%$ in women with 1 atypical foci. Involution or regression of the lobules in the background breast tissue in women with $\mathrm{AH}$ has also been shown to affect breast cancer risk. Women with greater lobular involution in the background breast tissue had a decreased RR of breast cancer (RR, 1.49; 95\% CI, 0.41-3.82) compared with those with no involution (RR, 7.79; 95\% CI, 3.56-14.81). ${ }^{19}$

\section{Risk Models}

Risk models currently available, such as the Gail model (Breast Cancer Risk Assessment Tool) and the Tyrer-Cuzick model, incorporate $\mathrm{AH}$ into their models and risk predictions but do not provide accurate estimates for these high-risk women. The TyrerCuzick model has been shown to overestimate the risk of breast cancer in women with $\mathrm{AH}$, whereas the Gail model was found to underestimate this risk..$^{20,21}$ Degnim et a ${ }^{22}$ used the Mayo Clinic Benign Breast Disease Cohort to develop a new model for breast cancer risk in these women, and validated it using the Nashville Breast Cohort. Variables included in the model were age at biopsy, age at biopsy squared, and number of foci with atypia. Ten-year risk estimates showed that the model demonstrated good discrimination $(0.63 ; 95 \% \mathrm{CI}, 0.57-0.70)$ and acceptable discrimination in the validation set with the Nashville Breast Cohort (0.59; 95\% CI, 0.510.67).22 These risk models will help inform both future discussions of individual risk for breast cancer with patients and further interventions between physicians and patients with $\mathrm{AH}$.

\section{Features of Subsequent Breast Cancers}

Women from the Mayo Clinic Benign Breast Disease Cohort have been followed for the development of subsequent breast cancers, with a median follow-up of 15.8 years. ${ }^{23}$ Ipsilateral breast cancers were predominant to the side of the previous benign breast biopsy in women with $\mathrm{AH}$, suggesting that $\mathrm{AH}$ is a precursor lesion in the development of invasive breast cancer. Time to development of DCIS from previous benign biopsy was shorter versus time to development of invasive breast cancer, which further suggests the pathway of progression to invasive breast cancer. Women with $\mathrm{AH}$ were also noted to be more likely to have ER-positive and progesterone receptor-positive disease. ${ }^{5,23}$

\section{Clinical Management}

\section{Surgery}

The upgrade rate of $\mathrm{ADH}$ becoming DCIS or invasive breast cancer on excisional biopsy ranges from $18 \%$ to $31 \%{ }^{24,25}$ Because the differences between $\mathrm{ADH}$ and DCIS are mainly the extent and size of the disease, excisional biopsy is often warranted for a definitive diagnosis. Standard of care is to excise all $\mathrm{ADH}$ lesions due to the higher upgrade rate and concern for DCIS. Recent literature has noted that some patients with ADH may opt for conservative management. Nguyen et $\mathrm{al}^{26}$ evaluated the clinical, mammographic, and histologic features of 140 patients with $\mathrm{ADH}$ diagnosed through vacuum-assisted breast biopsy (VABB) to determine factors that may predict presence of carcinoma. They found that the number of calcifications removed during biopsy $(<95 \%)$ was significantly associated with the rate of upgrade of ADH to carcinoma. Histologic features, such as number of terminal duct lobular units (TDLUs, >2), presence of significant cytologic atypia suspicious for carcinoma, and necrosis, were significantly correlated with a higher upgrade rate. Cases without these features were associated with an approximately $3 \%$ risk of carcinoma. ${ }^{26}$ Similar criteria were identified by investigators at Mayo Clinic, who noted an upgrade rate of 5\% among patients with $\mathrm{ADH}$ with the low-risk features. ${ }^{27}$

Menen et $\mathrm{al}^{28}$ reported on long-term follow-up of patients who underwent conservative management versus those who underwent surgical excision using 
these identified criteria. Using a multidisciplinary approach, they identified patients with $\mathrm{ADH}$ who were at low risk for upgrade and recommended conservative management and surveillance. Of 175 patients with $\mathrm{ADH}, 125$ were observed and 50 underwent excision, and a total of 14 breast cancer events were noted after a median follow-up of 3 years. A total of 6 women $(12 \%)$ in the surgery group developed breast cancer and 7 cancers $(5.6 \%)$ were noted in the observation group. ${ }^{28}$

Schiaffino et $\mathrm{al}^{29}$ showed similar findings in their cohort of 65 patients with $\mathrm{ADH}$ who underwent VABB and did not have residual calcifications after biopsy and underwent conservative management. Mean follow-up was 67 months and only 1 patient developed low-grade DCIS, revealing an upgrade rate of $<2 \%$. Although standard of care is to surgically excise $\mathrm{ADH}$, conservative management of select cases should be considered.

Surgical management of ALH/LCIS can be controversial. Previous studies have noted an upgrade rate to DCIS or invasive carcinoma of up to $50 \%$ in patients with lobular neoplasia, which led to the recommendation of surgical excision for all patients with ALH and LCIS. ${ }^{30}$ The limitations of early studies were selection for higher-risk cases for surgery and no evaluation for radiologic-pathologic discordance. Recent studies have shown that factors associated with a higher upgrade rate on excisional biopsy included extent of disease ( $>3$ TDLUs), whether the lobular lesion was target of initial biopsy, and suspicious findings on imaging. ${ }^{31-36}$ Incidental findings of lobular neoplasia on core biopsy was associated with a lower upgrade rate to carcinoma, and observation is recommended. ${ }^{31}$ Additionally, radiologic and pathologic concordance needs to be determined for consideration of conservative management.

\section{Surveillance}

The NCCN Clinical Practice Guidelines in Oncology (NCCN Guidelines) for Breast Cancer Screening and Diagnosis delineate the recommendations for screening high-risk populations, including women with $\mathrm{AH}$ and LCIS. ${ }^{37}$ Annual screening mammogram with consideration for tomosynthesis is recommended starting at time of diagnosis of ADH/ALH or LCIS, but not in women aged $<30$ years. Due to the elevated risk for breast cancer, clinical breast examination is recommended every 6 to 12 months.
Screening with breast MRI was previously recommended for women with elevated risk for breast cancer predominately due to family history of breast cancer, but did not include those with history of $\mathrm{AH}$ or LCIS. ${ }^{38}$ Due to insufficient evidence to make a recommendation for or against breast MRI screening in this high-risk population, American Cancer Society guidelines recommend discussion with healthcare provider, whereas NCCN Guidelines recommend considering a breast MRI for screening due to emerging evidence. ${ }^{37,39,40}$ Automated breast ultrasound has been evaluated for breast cancer screening as an adjunct to mammography in women with dense breast tissue, but further investigation is needed for those with $\mathrm{AH} / \mathrm{LCIS} .^{41}$ Molecular breast imaging is also currently being evaluated as an imaging modality to identify breast malignancies in women with $\mathrm{AH} /$ LCIS (ClinicalTrials.gov identifier: NCT00620087).

\section{Risk Reduction Therapy}

Multiple studies have evaluated selective ER modulators (SERMs) and aromatase inhibitors (AIs) for the prevention of breast cancer. The Breast Cancer Prevention Trial (BCPT) evaluated 13,388 women aged $\geq 35$ years with an elevated risk of breast cancer randomized to tamoxifen daily for 5 years or placebo. Tamoxifen reduced the incidence of invasive breast cancer by $49 \%(P<.0001)$ and of noninvasive breast cancer by $50 \%(P<.002) .{ }^{42}$ Among specific high-risk groups, tamoxifen reduced the incidence of breast cancer by $56 \%$ in women with LCIS and $86 \%$ in women with $\mathrm{AH}$. Tamoxifen reduces the incidence of ER-positive tumors, and we have seen that $\mathrm{AH}$ and LCIS often progress to ER-positive breast cancers.

The Study of Tamoxifen and Raloxifene (STAR) trial found that raloxifene showed a similar risk reduction of invasive breast cancer compared with tamoxifen after 5 years of therapy. On longterm follow-up of 81 months, tamoxifen was noted to be $25 \%$ more effective than raloxifene, and had a more durable response. Subset analysis of its preventive effects in women with $\mathrm{AH} / \mathrm{LCIS}$ showed that raloxifene and tamoxifen were equivalent. ${ }^{43} \mathrm{AIs}$ such as exemestane and anastrazole have also been evaluated in the MAP.3 and IBIS-2 trials, respectively. Exemestane daily versus placebo daily for 5 years showed a benefit in RR of breast cancer of 0.35 (95\% CI, 0.18-0.70) and 0.61 (95\% CI, 0.20-1.82) in women with $\mathrm{AH}$ and LCIS, respectively, although 
High-Risk Breast Lesions

\begin{tabular}{|c|c|c|c|c|c|}
\hline Trial & $\mathbf{N}$ & Agents & $\begin{array}{c}\text { Median } \\
\text { Follow-Up, } \\
\text { mo }\end{array}$ & $\begin{array}{l}\text { RR for Invasive } \\
\text { Breast Cancer } \\
\text { (95\% Cl) }\end{array}$ & $\begin{array}{l}\text { RR for AH or LCIS } \\
\quad(95 \% \mathrm{Cl})\end{array}$ \\
\hline NSABP- $1^{42}$ & 13,388 & Tamoxifen vs placebo & 84 & $0.57(0.46-0.70)$ & $0.25(0.10-0.52)$ \\
\hline $\mathrm{STAR}^{43}$ & 19,747 & Raloxifene vs tamoxifen & 81 & $1.24(1.05-1.47)$ & $\begin{array}{l}\text { Long-term tamoxifen provides } \\
\text { greater risk reduction }\end{array}$ \\
\hline IBIS-| $\left.\right|^{52}$ & 7,154 & Tamoxifen vs placebo & 192 & $0.71(0.60-0.83)$ & Not reported \\
\hline MAP. $3^{44}$ & 4,560 & Exemestane vs placebo & 35 & $0.35(0.18-0.70)$ & $0.61(0.20-1.82)$ \\
\hline IBIS-||45 & 3,864 & Anastrazole vs placebo & 60 & $0.50(0.32-0.76)$ & $0.31(0.12-0.84)$ \\
\hline
\end{tabular}

Abbreviations: AH, atypical hyperplasia; LCIS, lobular carcinoma in situ; RR, relative risk.

sample size was small for this subset. ${ }^{44}$ Anastrazole given daily for 5 years was also shown to be effective in reducing incidence of breast cancer in postmenopausal women with AH or LCIS (RR, 0.31; 95\% CI, 0.12-0.84). ${ }^{45}$ Table 2 summarizes the randomized trials of SERMs and AIs and their risk reduction of invasive breast cancer in these high-risk populations, and highlights that these medications provide the greatest benefit to women with AH or LCIS. Coopey et $\mathrm{al}^{11}$ reviewed 2,938 cases with atypical breast lesions and determined that the estimated 10 -year risk of women with $\mathrm{AH}$ who did not receive preventive therapy was $21.3 \%$, whereas those who received preventive therapy had a 10 -year risk of $7.5 \%(P<.001)$, revealing a significant reduction in breast cancer risk for women with $\mathrm{AH}$ and a need to recommend therapy. Clinical trials evaluating metformin and a novel somatostatin analog are ongoing as potential preventive therapy agents for women with $\mathrm{AH}$ or LCIS (ClinicalTrials.gov identifiers: NCT01905046, NCT01372644).

Despite the findings from these clinical trials showing the benefit of SERMs and AIs in preventing breast cancer, uptake of these medications is low. Waters et $\mathrm{a}^{46}$ noted that the uptake among US women was dismal at $0.2 \%$. Uptake was higher in academic centers, ranging from $13 \%$ to $25 \%$ in women with $\mathrm{AH} / \mathrm{LCIS}$, but there is still need for improvement. ${ }^{47,48}$ Our practice evaluated a performance improvement program that assessed women with AH/LCIS, including whether they were recommended and prescribed preventive therapy. Feedback regarding the data collected was given to individual providers with the goal of increasing the recommendation and uptake of preventive therapy. With this approach, $98 \%$ of women diagnosed with AH or LCIS were recommended preventive therapy, and uptake was $82 \%$ in newly diagnosed patients and $48 \%$ in patients who were previously diagnosed but may have declined preventive therapy in the past. ${ }^{49}$ Presentation of the recent data showing increased risk of breast cancer in this population, ${ }^{3,5,11-13}$ together with our strong recommendation and the significant benefit of these medications shown in these women, has increased uptake in our center, and this approach should be considered in other clinics as well.

\section{Conclusions}

$\mathrm{AH}$ and LCIS have an increased RR of breast cancer and a cumulative incidence of breast cancer of $30 \%$ at 25 years, leading to a $1 \%$ to $2 \%$ increase per year. Age at diagnosis and number of atypical foci have been shown to modify risk estimates in individuals with AH/LCIS, but accurate risk assessments to identify those who will develop breast cancer are still lacking. Education of women diagnosed with $\mathrm{AH} / \mathrm{LCIS}$ should involve discussion of the population risk until better individual risk estimates can be developed.

Management of women with AH/LCIS using surgical excision is changing, with more data suggesting multidisciplinary review and evaluation for radiologic and pathologic concordance should be used to identify patients for conservative management. Women should continue to undergo screening mammograms, and breast MRI should also be discussed and considered in this population. Finally, risk-reduction therapy with SERMs and AIs has been shown to have a significant effect in these women, and therefore it is important to review these benefits with patients and increase uptake of these medications. 


\section{Thomas}

\section{References}

1. Gutwein LG, Ang DN, Liu H, et al. Utilization of minimally invasive breast biopsy for the evaluation of suspicious breast lesions. Am J Surg 2011;202:127132 .

2. Allred DC, Mohsin SK, Fuqua SA. Histological and biological evolution of human premalignant breast disease. Endocr Relat Cancer 2001;8:47-61.

3. Hartmann LC, Radisky DC, Frost MH, et al. Understanding the premalignant potential of atypical hyperplasia through its natural history: a longitudinal cohort study. Cancer Prev Res (Phila) 2014;7:211-217.

4. Bombonati A, Sgroi DC. The molecular pathology of breast cancer progression. J Pathol 2011;223:307-317.

5. Hartmann LC, Degnim AC, Santen RJ, et al. Atypical hyperplasia of the breast-risk assessment and management options. N Engl J Med 2015;372:7889.

6. Dupont WD, Page DL. Risk factors for breast cancer in women with proliferative breast disease. N Engl J Med 1985;312:146-151.

7. Simpson JF. Update on atypical epithelial hyperplasia and ductal carcinoma in situ. Pathology 2009;41:36-39.

8. Rubin E, Visscher DW, Alexander RW, et al. Proliferative disease and atypia in biopsies performed for nonpalpable lesions detected mammographically. Cancer 1988;61:2077-2082.

9. Hartmann LC, Sellers TA, Frost MH, et al. Benign breast disease and the risk of breast cancer. N Engl J Med 2005;353:229-237.

10. Barr FE, Degnim AC, Hartmann LC, et al. Estrogen receptor expression in atypical hyperplasia: lack of association with breast cancer. Cancer Prev Res (Phila) 2011;4:435-444.

11. Coopey SB, Mazzola E, Buckley JM, et al. The role of chemoprevention in modifying the risk of breast cancer in women with atypical breast lesions. Breast Cancer Res Treat 2012;136:627-633.

12. Menes TS, Kerlikowske K, Lange J, et al. Subsequent breast cancer risk following diagnosis of atypical ductal hyperplasia on needle biopsy. JAMA Oncol 2017;3:36-41.

13. Degnim AC, Dupont WD, Radisky DC, et al. Extent of atypical hyperplasia stratifies breast cancer risk in 2 independent cohorts of women. Cancer 2016;122:2971-2978.

14. London SJ, Connolly JL, Schnitt SJ, Colditz GA. A prospective study of benign breast disease and the risk of breast cancer. JAMA 1992;267:941-944.

15. Mazzola E, Coopey SB, Griffin M, et al. Reassessing risk models for atypical hyperplasia: age may not matter. Breast Cancer Res Treat 2017;165:285-291.

16. Collins LC, Baer HJ, Tamimi RM, et al. Magnitude and laterality of breast cancer risk according to histologic type of atypical hyperplasia: results from the Nurses' Health Study. Cancer 2007;109:180-187.

17. Ghosh K, Vierkant RA, Frank RD, et al. Association between mammographic breast density and histologic features of benign breast disease. Breast Cancer Res 2017;19:134.

18. Vierkant RA, Degnim AC, Radisky DC, et al. Mammographic breast density and risk of breast cancer in women with atypical hyperplasia: an observational cohort study from the Mayo Clinic Benign Breast Disease (BBD) cohort. BMC Cancer 2017;17:84.

19. Milanese TR, Hartmann LC, Sellers TA, et al. Age-related lobular involution and risk of breast cancer. J Natl Cancer Inst 2006;98:1600-1607.

20. Pankratz VS, Hartmann LC, Degnim AC, et al. Assessment of the accuracy of the Gail model in women with atypical hyperplasia. J Clin Oncol 2008;26:5374-5379.

21. Boughey JC, Hartmann LC, Anderson SS, et al. Evaluation of the Tyrer-Cuzick (International Breast Cancer Intervention Study) model for breast cancer risk prediction in women with atypical hyperplasia. J Clin Oncol 2010;28:35913596.

22. Degnim AC, Winham SJ, Frank RD, et al. Model for predicting breast cancer risk in women with atypical hyperplasia. J Clin Oncol 2018;36:1840-1846.

23. Visscher DW, Frost MH, Hartmann LC, et al. Clinicopathologic features of breast cancers that develop in women with previous benign breast disease. Cancer 2016;122:378-385.

24. McGhan LJ, Pockaj BA, Wasif N, et al. Atypical ductal hyperplasia on core biopsy: an automatic trigger for excisional biopsy? Ann Surg Oncol 2012;19:3264-3269.

25. Margenthaler JA, Duke D, Monsees BS, et al. Correlation between core biopsy and excisional biopsy in breast high-risk lesions. Am J Surg 2006;192:534-537.

26. Nguyen CV, Albarracin CT, Whitman GJ, et al. Atypical ductal hyperplasia in directional vacuum-assisted biopsy of breast microcalcifications: considerations for surgical excision. Ann Surg Oncol 2011;18:752-761.

27. Pena A, Shah SS, Fazzio RT, et al. Multivariate model to identify women at low risk of cancer upgrade after a core needle biopsy diagnosis of atypical ductal hyperplasia. Breast Cancer Res Treat 2017;164:295-304.
28. Menen RS, Ganesan N, Bevers T, et al. Long-term safety of observation in selected women following core biopsy diagnosis of atypical ductal hyperplasia Ann Surg Oncol 2017;24:70-76.

29. Schiaffino S, Massone E, Gristina L, et al. Vacuum assisted breast biopsy (VAB) excision of subcentimeter microcalcifications as an alternative to open biopsy for atypical ductal hyperplasia. Br J Radiol 2018;91:20180003.

30. Houssami N, Abraham LA, Onega T, et al. Accuracy of screening mammography in women with a history of lobular carcinoma in situ or atypical hyperplasia of the breast. Breast Cancer Res Treat 2014;145:765-773.

31. Middleton LP, Sneige N, Coyne R, et al. Most lobular carcinoma in situ and atypical lobular hyperplasia diagnosed on core needle biopsy can be managed clinically with radiologic follow-up in a multidisciplinary setting. Cancer Med 2014;3:492-499.

32. Calhoun BC, Collie AM, Lott-Limbach AA, et al. Lobular neoplasia diagnosed on breast core biopsy: frequency of carcinoma on excision and implications for management. Ann Diagn Pathol 2016;25:20-25.

33. Murray MP, Luedtke C, Liberman L, et al. Classic lobular carcinoma in situ and atypical lobular hyperplasia at percutaneous breast core biopsy: outcomes of prospective excision. Cancer 2013;119:1073-1079.

34. Rendi MH, Dintzis SM, Lehman CD, et al. Lobular in-situ neoplasia on breast core needle biopsy: imaging indication and pathologic extent can identify which patients require excisional biopsy. Ann Surg Oncol 2012;19:914-921.

35. Shah-Khan MG, Geiger XJ, Reynolds C, et al. Long-term follow-up of lobular neoplasia (atypical lobular hyperplasia/lobular carcinoma in situ) diagnosed on core needle biopsy. Ann Surg Oncol 2012;19:3131-3138.

36. Subhawong AP, Subhawong TK, Khouri N, et al. Incidental minimal atypical lobular hyperplasia on core needle biopsy: correlation with findings on followup excision. Am J Surg Pathol 2010;34:822-828.

37. Bevers TB, Helvie M, Bonaccio E, et al. NCCN Clinical Practice Guidelines in Oncology: Breast Cancer Screening and Diagnosis, Version 2.2018. Accessed October 22, 2018. To view the most recent version of these guidelines, visit NCCN.org.

38. Saslow D, Boetes C, Burke W, et al. American Cancer Society guidelines for breast screening with MRI as an adjunct to mammography. CA Cancer J Clin 2007;57:75-89.

39. Port ER, Park A, Borgen PI, et al. Results of MRI screening for breast cancer in high-risk patients with LCIS and atypical hyperplasia. Ann Surg Oncol 2007;14:1051-1057.

40. King TA, Muhsen S, Patil S, et al. Is there a role for routine screening MRI in women with LCIS? Breast Cancer Res Treat 2013;142:445-453.

41. Shin HJ, Kim HH, Cha JH. Current status of automated breast ultrasonography. Ultrasonography 2015;34:165-172.

42. Fisher B, Costantino JP, Wickerham DL, et al. Tamoxifen for prevention of breast cancer: report of the National Surgical Adjuvant Breast and Bowel Project P-1 study. J Natl Cancer Inst 1998;90:1371-1388.

43. Vogel VG, Costantino JP, Wickerham DL, et al. Update of the National Surgical Adjuvant Breast and Bowel Project Study of Tamoxifen and Raloxifene (STAR) P-2 trial: preventing breast cancer. Cancer Prev Res (Phila) 2010;3:696-706.

44. Goss PE, Ingle JN, Ales-Martinez JE, et al. Exemestane for breast-cancer prevention in postmenopausal women. N Engl J Med 2011;364:2381-2391.

45. Cuzick J, Sestak I, Forbes JF, et al. Anastrozole for prevention of breast cancer in high-risk postmenopausal women (IBIS-II): an international, double-blind, randomised placebo-controlled trial. Lancet 2014;383:1041-1048.

46. Waters EA, Cronin KA, Graubard BI, et al. Prevalence of tamoxifen use for breast cancer chemoprevention among U.S. women. Cancer Epidemiol Biomarkers Prev 2010;19:443-446.

47. Reimers LL, Sivasubramanian PS, Hershman D, et al. Breast cancer chemoprevention among high-risk women and those with ductal carcinoma in situ. Breast J 2015;21:377-386.

48. Trivedi MS, Coe AM, Vanegas A, et al. Chemoprevention uptake among women with atypical hyperplasia and lobular and ductal carcinoma in situ. Cancer Prev Res (Phila) 2017;10:434-441.

49. Brewster AM, Thomas $\mathrm{P}$, Brown $\mathrm{P}$, et al. A system-level approach to improve the uptake of antiestrogen preventive therapy among women with atypical hy perplasia and lobular cancer in situ. Cancer Prev Res (Phila) 2018;11:295-302.

50. Page DL, Dupont WD, Rogers LW, Rados MS. Atypical hyperplastic lesions of the female breast. A long-term follow-up study. Cancer 1985;55:2698-2708.

51. Worsham MJ, Abrams J, Raju U, et al. Breast cancer incidence in a cohort of women with benign breast disease from a multiethnic, primary health care population. Breast J 2007;13:115-121.

52. Cuzick J, Sestak I, Cawthorn S, et al. Tamoxifen for prevention of breast cancer: extended long-term follow-up of the IBIS-I breast cancer prevention trial. Lancet Oncol 2015;16:67-75 